\title{
Alvarenga e Ranchinho no dial da Rádio Nacional: um convite a ouvir a História
}

\author{
Alvarenga and Ranchinho in the Radio Nacional dial: \\ an invitation to hear the History \\ Carlos Gregório dos Santos Gianelli ${ }^{1}$ \\ gianelli.87@hotmail.comTelefone
}

Resumo

Este artigo tem como principal objetivo discutir brevemente alguns procedimentos de análise de programas de rádio e sua relação com a História. Para isso, serão apresentados alguns autores que trabalham com os temas da canção, paródia, performance e que forneçam pistas da participação do público em programas de auditório veiculados pela Rádio Nacional. O material de exemplo analisado aqui é o programa de estreia da dupla de humoristas Alvarenga e Ranchinho na Rádio Nacional no ano de 1947.

Palavras-chave: história e música, Rádio Nacional, Alvarenga e Ranchinho.

\begin{abstract}
This article has as main objective to discuss briefly some procedures for analyzing radio programs and their relationship with history. Some authors it working with the themes of the song, parody, performance and provide clues of public participation in talk shows aired by Radio Nacional will be presented. The sample material analyzed here is the program's debut duo of comedians Alvarenga and Ranchinho on Radio Nacional in 1947.
\end{abstract}

Keywords: history and music, Radio Nacional, Alvarenga and Ranchinho. 


\section{Sobre História e Música}

Uma pesquisa histórica pode partir das mais diversas perspectivas para a análise dos fatos e dos processos ocorridos para depois então tomar corpo em uma produção textual por meio da narrativa histórica. A escrita da História por meio de documentos escritos já é amplamente difundida visto que não se faz necessária uma tradução de linguagem: parte de palavras escritas e resulta em outras palavras escritas. Nesse ponto é que o campo de estudos de História e Música demonstra sua especificidade quando utiliza não somente documentos escritos, mas também documentos sonoros, tais como, o fonograma de canções ou programas de rádio. A transfiguração necessária para o entendimento do leitor, que o pesquisador deve fazer da manifestação sonora para a expressão escrita, coloca-se como primeira questão metodológica a ser feita. Como transcrever expressões fonéticas muitas vezes de uma espontaneidade indescritível em palavras? Ou ainda, como inserir o documento sonoro, agora transcrito, em um diálogo com outros documentos escritos? Essas e outras questões permeiam este artigo, que tem como principal documento sonoro uma gravação de programa de rádio veiculado pela Rádio Nacional tendo como atração a dupla de humoristas Alvarenga e Ranchinho.

Apesar de ser um campo relativamente recente, comparado a outros (como a Literatura e a História da Arte), os estudos de História e Música já possuem alguns parâmetros de análise muito bem estruturados no que diz respeito à produção historiográfica brasileira. Autores como Marcos Napolitano, Arnaldo Contier e José Geraldo Vinci de Moraes, para citar somente esses três, fornecem muitas ferramentas de análise fundamentais para o pesquisador que se disponha a pesquisar sobre o tema. Ainda existem outros grandes historiadores que trabalham com o tema, sem contar com pesquisadores de outras áreas como sociologia, comunicação e literatura que contribuem em muito com as discussões. Escolhi citar os três nomes acima por se tratar de autores básicos e fundamentais para a pesquisa histórica envolvendo música no Brasil.

Dos três autores, trago algumas contribuições de Napolitano. Esse atraso da História com relação ao uso de documentos sonoros para sua produção de pesquisa é sinalizado pelo autor no livro "Fontes Históricas" organizado por Carla Pinsky:

\footnotetext{
No campo dos "Estudos em música popular", os historiadores de ofício mais uma vez chegaram atrasados. A área de Letras e as Ciências Sociais já haviam descoberto a canção e consagrado algumas abordagens antes dos historiadores utilizarem a música como fonte para História. (Napolitano in Pinsky, 2005, p.236)
}

Do mesmo autor, o livro "História e Música" serve como leitura básica para o historiador que trabalhará na área de pesquisa envolvendo representações musicais. O autor fornece direcionamentos bem básicos para o desenvolvimento de um projeto. No começo do livro é traçado um pequeno panorama do desenvolvimento do conceito de música popular: tanto o processo envolvido na produção musical em si, quanto as diferentes apropriações que o termo popular teve em diversos contextos é discutido nessa primeira parte. O autor lembra que a produção historiográfica nessa área ainda é muito escassa, sendo ela ainda portadora de muitas possibilidades de pesquisa. Nesse ponto, aliás, Napolitano destaca o baixo número de pesquisas realizadas com relação à época do programa de rádio aqui escolhido: “[...] faltam trabalhos historiográficos de fôlego, que articulem a análise da produção musical às questões estéticas e os hábitos de consumo para outros momentos importantes da história da música brasileira, como os anos 30/40 [...]" (Napolitano, 2001, p.37). A obra tem como seu desfecho uma proposta metodológica bem clara de como se trabalhar com música em pesquisas históricas. Napolitano divide por subcapítulos e tópicos cada item que merece atenção para análise explicitando um método para cada tipo de fonte.

\section{Parâmetros de análise de um programa de rádio}

Para analisar o programa de rádio apresentado pela dupla Alvarenga e Ranchinho elenquei três parâmetros: canção, performance e participação do público. Dos três termos, participação do público, talvez seja o mais difuso por não se tratar de uma categoria de análise em específico, no entanto, sendo o programa de rádio transmitido nos estúdios equipados com auditório e com a presença de uma plateia, tal característica se faz muito pertinente para a análise das gravações. 
Durante muito tempo, nos estudos de História e Música a canção foi utilizada como documento partindo somente de uma análise textual da letra sem levar em conta outros elementos como o arranjo instrumental ou a performance. Essa perspectiva foi, de certa maneira, herdada dos estudos de literatura nos quais interessava principalmente o elemento textual que a canção possuía em contrapartida ao elemento sonoro. Nos recentes estudos historiográficos musicais a questão sonora (envolvendo dentre outros parâmetros a performance), firma-se como uma perspectiva válida e enriquecedora dos debates nesse campo. No entanto, assinalo que de modo algum a letra da canção deve ser abandonada quando analisada por um historiador. Neste caso, como a dupla Alvarenga e Ranchinho utiliza amplamente do artifício da paródia em suas apresentações, a análise da letra cabe perfeitamente dentro do espectro analítico fornecendo elementos muito significativos e até mesmo reveladores da produção humorística dos artistas. Lembro ainda que os autores utilizados neste artigo são apenas uma indicação inicial de possibilidades de pesquisa.

O primeiro autor que de certo modo prepara o terreno para a análise das canções parodiadas vem do campo da literatura. Affonso Romano de Sant'Anna, com seu livro "Paródia, paráfrase \& cia", esquematiza de modo bem sistemático os parâmetros para a definição de cada termo citado no título. A parte do livro dedicada à paródia é fundamental para o pesquisador que depara com essa ferramenta amplamente utilizada por muitos artistas, em especial, os da área humorística. Se as canções, por exemplo, não fizessem uso do artifício da paródia, este autor selecionado não seria de grande valia como é nesse caso.

Trago alguns pontos levantados por Paul Zumthor em seu livro "Performance, recepção e leitura", que mesmo partindo de uma análise calcada no campo da literatura coloca-se de maneira muito relevante na análise, por exemplo, na performance de um programa de rádio. Sobre essa questão Zumthor destaca alguns pontos levantados por Dell Hymes em 1973 dentre eles que:

A performance se situa num contexto ao mesmo tempo cultural e situacional: nesse contexto ela aparece como "emergência", um fenômeno que sai desse contexto ao mesmo tempo em que nele encontra lugar. Algo se criou, atingiu a plenitude e, assim, ultrapassa o curso comum dos acontecimentos. (Zumthor, 2007,p.31)

O terceiro ponto que utilizo como baliza de análise para o programa de rádio é a participação do público. Por se tratar especificamente de programas de auditório, a intensa relação entre a plateia e os artistas deve fazer parte do conjunto analítico. Faz-se necessária uma breve contextualização do espaço que eles ocupam: os estúdios da Rádio Nacional. Para isso, três livros podem dar algumas pistas do ambiente no qual todos esses personagens estavam inseridos. O livro "Por trás das ondas da Rádio Nacional” de Miriam Goldfeder, já é uma referência no assunto e aborda dentre vários temas a questão dos programas de auditório. Apesar de a obra focar na relação de consumo dentro da lógica da indústria cultural, tendo como objeto de análise a disputa existente entre as candidatas à Rainha do Rádio, a autora toca em alguns pontos pertinentes em relação à interação do público presente no auditório e os artistas. Outro livro que ajuda a mapear esse contexto é o título "Rádio Nacional: o Brasil em Sintonia" de Luiz Carlos Saroldi e Sonia Virgínia Moreira. O livro conta a trajetória da Rádio Nacional desde a sua fundação até o seu desmonte em meados dos anos de 1960. Quase sendo um inventário da Rádio Nacional o livro traz dados interessantes sobre a imensa estrutura da emissora, bem como dados relativos à organização de sua programação e índices de audiência. Por fim, o livro "Bastidores do Rádio" de Renato Murce, oferece uma perspectiva interessante e bem aproximada dos programas da Rádio Nacional por meio do ponto de vista de um funcionário. Apesar da visão privilegiada que o livro fornece, por se tratar de um foco muito aproximado do cotidiano da rádio, é necessário certo cuidado com as palavras de Murce que carregam um amargor por não fazer mais parte da Rádio e por não estar mais no auge e nem na ativa com a emissora. Todavia, é uma perspectiva interessante de um funcionário muito crítico da Rádio Nacional que apesar de apontar suas falhas volta e meia lembra em seu texto do imenso apreço e carinho que tem pelo trabalho que exerceu por mais de vinte anos.

\section{Os programas de rádio}

O programa de rádio utilizado neste artigo para análise foi adquirido por intermédio de uma empresa especializada em gravações antigas: a Collector’s Studios da cidade do Rio de Janeiro. O difícil acesso a este 


\section{Artigos}

tipo de acervo é um dos principais entraves que o pesquisador que se propõe a estudá-los enfrenta. O Museu de Imagem e Som (MIS), do Rio de Janeiro, não possui uma organização adequada do seu acervo que facilite o seu acesso. Depois de algumas tentativas por telefone, fui informado de que o Museu não possui um catálogo virtual (bastava um arquivo em $p d f$, por exemplo) que possa ser enviado para o pesquisador. E, mesmo realizando uma pesquisa in loco não seria possível realizar uma cópia do áudio (condição absurda que o Museu impõe tendo em vista o grande trabalho de escuta que o pesquisador deve realizar exaustivamente quando analisa esse tipo de documento). Além do museu, para que se tenha acesso a esse tipo de arquivo o pesquisador acaba ficando a mercê de acervos pessoais ou de empresas especializadas como o caso da Collector's. Essa questão do acesso aos acervos de Rádio e Televisão em território brasileiro é muito pertinente. Visto que a disponibilização deveria ser obrigatória a partir do fato que as emissoras operam sob concessão pública, ou seja, disponibilizar o seu acervo para pesquisa, sem fins comerciais, seria o mínimo que elas poderiam fazer, mas não o fazem. É necessário percorrer um labirinto burocrático ou adentrar uma densa rede de favores para ter acesso aos arquivos de mídia.

De volta para os programas em específico, o acervo da Collector's possuía oito programas de rádio apresentados pela dupla Alvarenga e Ranchinho sendo quatro deles em sequência. O programa tinha uma frequência semanal, toda terça feira, às vinte horas, e era transmitido ao vivo do auditório da Nacional. A escolha da dupla Alvarenga e Ranchinho acabou sendo uma consequência da trajetória de pesquisa que venho traçando desde o final da minha graduação em História pela Universidade Federal de Santa Catarina, quando pesquisei sobre a gênese da música sertaneja no recém-formado mercado fonográfico brasileiro no fim da década de 1920, o que acabou resultando na minha dissertação de Mestrado defendida pela Universidade do Estado de Santa Catarina.

Dos oito programas apresentados pela dupla de humoristas foi escolhido um para servir de exemplo como material de análise. Escolhi esse programa por fornecer um material muito diversificado em suas representações artísticas e por demonstrar muito claramente os parâmetros que um programa de rádio apresentado em auditório poderia ter. Dos quatro primeiros veiculados pela Rádio Nacional com a dupla Alvarenga e Ranchinho o escolhido para esse artigo é o programa de estreia dos artistas. Para melhor localização dos acontecimentos dentro dos programas, nos anexos deste artigo se encontra um breve quadro analítico do programa com a minutagem específica de cada acontecimento.

As canções analisadas nesse programa tiveram como ponto central a questão da paródia. Poderia ter sido analisada também, por exemplo, o cunho sócio-político de outras canções entoadas nesse e em outros programas, todavia, optou-se pela análise específica da paródia, visto que é um artifício amplamente utilizado por humoristas não fugindo à regra para a dupla aqui presente. Em seu livro "Paródia, paráfrase \& cia", Affonso Romano de Sant'Anna conceitua com precisão os conceitos que dão título a obra utilizando exemplos da literatura. Tomando emprestado os conceitos em análises das letras das canções é possível observar muitos pontos interessantes e refletir como os humoristas trabalham e instrumentalizam toda a construção da nova letra na canção parodiada. Sant'Anna classifica a paródia partindo de uma esquematização presente no Dictionary of World Literature de Josephe Shipley:

Verbal - com alteração de uma ou outra palavra do texto;

Formal - em que o estilo e os efeitos técnicos de um escritor são usados como forma de zombaria

Temática - em que se faz a caricatura da forma e do espírito de um autor. (Sant'Anna, 2007,p.12)

A primeira música parodiada no programa de estreia da dupla Alvarenga e Ranchinho é a canção "Amado Mio" presente no filme Gilda de 1946 (um ano antes da veiculação do programa) que tem o seu enredo permeado pelos ambientes dos cassinos presentes nas cidades de Buenos Aires e Montevidéu. Sobre a escolha desta canção para ser parodiada pela dupla cabem duas observações. A primeira é que o artista quando faz a paródia de uma canção não faz essa escolha à toa. É necessária uma empatia do público, ou mesmo um breve conhecimento da canção que será modificada para que haja o efeito humorístico esperado. É possível deduzir que o filme "Gilda" tenha tido certa repercussão no ano anterior para que a dupla escolhesse uma das músicas presentes na história para ser parodiada. A segunda observação que cabe sobre 
a escolha do filme diz respeito ao novo ambiente que a classe artística carioca enfrentava com o fechamento dos cassinos. O decreto-lei assinado pelo então presidente Eurico Gaspar Dutra no ano de $1946^{2}$ encerrou o funcionamento destes estabelecimentos que eram o celeiro de grandes artistas do rádio e do cinema. Para citar a maior exportação desta época, Carmem Miranda foi uma das cantoras que criou renome em locais como o Cassino da Urca antes de sua projeção internacional.

A dupla Alvarenga e Ranchinho não era diferente, chegando até mesmo a excursionar com o grupo de artistas do Cassino para outros países como Argentina e Portugal. Os cassinos como espaço de produção e circulação do meio cultural tinham papel fundamental para a classe artística da época. O seu fechamento obrigou a classe a buscar novos locais para suas apresentações e divulgação do seu trabalho. "De uma hora para a outra, artistas, cantores e músicos viram-se privados de um mercado de trabalho que apenas o teatro de revistas não poderia preencher [...]" (Moreira;Saroldi, 1984, p.76) Pode-se deduzir, inclusive, que alguns dos artifícios utilizados pela dupla de humoristas no auditório da Rádio Nacional vinham de uma prática de interação com o público dos cassinos (público este completamente diferente dos que frequentavam os auditórios, vale frisar). As canções, parodiadas ou não, sempre integravam a narrativa dos esquetes apresentados pela dupla em seus programas. A paródia de "Amado Mio" entra no momento em que Alvarenga conta para Ranchinho que está namorando uma mulher muito bonita e inteligente que em suas palavras "parecia até a Girda!” O eu lírico da paródia é a mulher que teria cantado o seguinte para Alvarenga:

Amado mio, se vancê for bonzinho

eu vou te levar, na confeitaria pra ver as criancinha comer doce

E se vance, não ficá comportado

Eu vou te mostrá o retrato do Prínio Sargado

(Collectors, 25/02/1947, 12:15 - 12:45)

Das três classificações apresentadas por Affonso Romano de Sant'Anna a paródia da canção “Amado Mio" se enquadraria no tipo verbal tendo em vista que não é satirizada entonação ou não é objeto de piada o autor ou intérprete da versão original. A letra original da canção entoada por Rita Hayworth é a seguinte:

Amado mio, love me forever

And let forever begin tonight

Amado mio, when we're together

I'm in a dream world of sweet delight ${ }^{3}$

A piada presente na paródia reside na narrativa propriamente dita da esquete na qual, no momento em que a canção surge, a mulher de Alvarenga daria uma bronca caso ele não se comportasse corretamente. O riso emana da linguagem caipira adotada pelos artistas e que nessa paródia aparece muito claramente nas expressões vancê e Prínio Sargado e também na utilização de um personagem político colocado como tão feio que poderia ser utilizado de "castigo" por alguém.

A segunda canção parodiada pela dupla em seu programa de estreia é a música "Adíos Pampa Mia”, um tango com letra de Francisco Canaro e Ivo Pelay e música de Mariano Mores composto em 1945. Dessa vez, na narrativa da esquete, a amada de Alvarenga teria o abandonado cantando a seguinte canção:

Adeus Pampa Mia

Me voy, e já me voy indo tarde

Chega de tanto passá fome

Adeus sede por farta d'água

Adeus pão preto que eu comia

Comia e não reclamava

2 Decreto lei: http://www.planalto.gov.br/ccivil_03/decreto-lei/del9215.htm - Acesso em 13/06/2014.

3 http://yricsplayground.com/alpha/songs/a/amadomio.shtml 
Artigos

Senão a "renha" baixava

Adeus mantega sebosa

Adeus, cidade maravilhosa

(Collectors, 25/02/1947, 14:09 - 14:55)

Apesar de a música ser estrangeira, foi gravada uma versão em português pelo cantor brasileiro Francisco Alves. Mais uma vez, percebe-se que a escolha da música não é aleatória, sendo ela um sucesso na voz de um dos cantores de maior prestígio da época no rádio. Esta paródia, também do tipo verbal, além de possuir em sua letra a pronúncia das palavras no estilo do estereótipo caipira, alfineta algumas mazelas sociais como nos versos "Adeus sede por farta d'água/Adeus pão preto que eu comia”. Outro ponto forte presente nesta e em outras canções é a referência à cidade na qual o programa era veiculado. O Rio de Janeiro ainda como capital federal, era a principal referência para a classe artística e para os ouvintes da Rádio Nacional. Sobre isso, José Ramos Tinhorão em um artigo sobre os programas de auditório para o Jornal do Brasil em 1977 relata um encontro interessante ocorrido no nordeste do Brasil entre um oficial do Exército e uma moradora local:

\begin{abstract}
Segundo o ex-locutor Floriano Faissal, que relatou o caso para a repórter Maria Helena Dutra, o Major Menescal conhecera naquela sua visita a uma fazenda de cacau baiana "uma moça muito interessante e falante, com sotaque carioca." Então lhe perguntou a quanto tempo tinha vindo do Rio. A moça riu muito e respondeu: "Nunca fui ao Rio na minha vida!" "Mas a senhora fala como uma carioca..." "Major, e a Rádio Nacional não nos ensina direitinho?", respondeu ela." (Tinhorão, 1977, p.30)
\end{abstract}

A terceira e última canção parodiada pela dupla Alvarenga e Ranchinho em seu programa de estreia faz a ponte com o segundo conceito que defendo como fundamental para a análise de programas de rádio: a questão da performance. Outras canções presentes neste programa não sofrem do artifício da paródia em si. São satirizadas de outras maneiras por meio da paráfrase ou estilização e por isso não foram analisadas aqui.

A música "Pa-Ran-Pan-Pan" de Sérgio de Carlo primeiramente é apresentada ao público em sua versão original para depois ser parodiada. No momento em que é entoada a canção original, Alvarenga requebra com os ombros, aparentemente no ritmo de mambo que a canção possui. Ranchinho não perdoa e faz piada com a coreografia dizendo: "Ué, mas que negócio é esse? Ué, nunca vi ninguém requebrá com os ombro?" Antes mesmo da paródia ser feita a plateia presente no auditório já cai na gargalhada com a performance corporal do artistas que ao requebrar no "estilo Carmem Miranda” já executa um certo tipo de paródia antes mesmo de entoar a canção com a letra modificada. Desse modo, a paródia de "Pa-Ran-Pan-Pan" é ao mesmo tempo Verbal, pois substituirá as palavras em sua nova versão e Temática na medida em que por meio da performance é satirizada a dança presente no universo da canção. A versão original apresentada ao público tem a seguinte letra:
Pa-Ran-Pan-Pan (Sérgio de Carlo)
De todo negro de Habana
Yo soy el negro mas guapetón
Yo soy el más cumbanchero
Que se pasea por Malecón
Las negras se vuelven locas
Por mi cintura montada en flan
Por que dicen que yo tengo
Paranpanpan-pan-pan ${ }^{4}$

\footnotetext{
4 Referências de letra e autoria:

http://letras.mus.br/ney-matogrosso/1652259/?domain_redirect=1

http://www.uesb.br/links/2010/05/semana_dos_museus.pdf

http://www.discogs.com/viewimages?release $=3329462$
} 
A paródia feita pela dupla contém alguns elementos muito interessantes a serem analisados. O primeiro deles é o conteúdo da letra que faz piada com o universo dos artistas sendo, nesse caso, uma piada voltada para o universo da dupla e dos artistas do casting da Rádio Nacional. Outro fator presente na paródia é a sua interação com a plateia presente quando entoado o último verso (os diálogos entre Alvarenga e Ranchinho encontram-se em itálico):

O artista mesmo casado é admirado tem muitas fã

Embora ele sendo forte, mostrando porte que é can-can

Mas quando ele chega em casa de madrugada quase manhã

Muié pega na vassoura e pa-ran-pan-pan-pan-pan

- Eita se é..

- Quantos artista tem ai dentro que acontece isso..

- É dúzia de vassoura por semana!

- Louzada tá la mesmo ó la..

Nega, larga essa vassoura

Não me deixe de salmora

Óia o que o vizinho está espiando

Meu cartaz baixando

Nega, eu não puedo mais

-Fazê um versinho agora prás mocinha..tão com medo é?

Mocinha que sai de noite com o namorado prá passeá

Que vai no seu automóvel fazer a ceia lá no Juá

E quando ele traz de volta para Avenida Maracanã

Se ela não for esperta pa-ran-pan-pan-pan-pan

- $\hat{E} !$ (os dois)

(risos e aplausos da plateia)

saudação final:

- Até terça...

- Até terça...

(Collectors, 25/02/1947, 19:27 - 20:56)

Essa rápida interação com o público na fala “-Fazê um versinho agora prás mocinha..tão com medo é?” mostra, ainda que te maneira breve, a possibilidade que a dupla tinha de interação com a plateia presente no auditório. Antes, logo no início do programa os caipiras não perdoam algumas pessoas que teriam chego atrasado falando em rede nacional:

- Mas, vamo esperar que tem mais três que vão sentar agora..

(risos da plateia)

- Tão chegando tarde hein?

(risos da plateia)

- Já perderam dez minuto!

(Collectors, 25/02/1947, 09:48 - 10:03) 
Artigos

Momentos antes, na canção de saudação ao público, a dupla Alvarenga e Ranchinho interage com as moças do auditório colocando elas, de certo modo, numa situação levemente constrangedora:

- Mas como tem moça bonita ai

- Ah se tem!

- Tem cada torrerminho ai..

- Mas é mermo né..

- Bom, também tem umas pelanca ai..

$[\ldots]$

- Ê Nacional..

- Tem uma moça ali que não tira o olho de mim, olha lá!

- $\hat{\mathrm{E}}$..

- Ah, pera lá, ela tá sentada ali

- Não aponta, farta de educação

(risos da plateia)

- Não ia apontá, ia mostrá uai..

- Mas, se é lá naquele bolo ali, ta oiando é pra mim!

- Essa que eu falei tá olhando pra mim..

- Cê acha que eu sou surdo e não enxergo?

- Não, óia bem rapaz, tira um fiapo que não é pra mim, olha lá

- Ah, é pra ocê mermo...Agora que eu vi

- Eu falei que era né...

- Ela é vesga?

(risos da plateia)

(Collectors, 25/02/1947, 01:10 - 04:05)

Como será que era esse auditório no qual a dupla Alvarenga e Ranchinho, juntamente do locutor Jorge Curi, interagiam com o público com suas canções, esquetes e piadas? Como já dito aqui, os livros de Luiz Carlos Saroldi e Sonia Virgínia Moreira, Miriam Golfeder, além do relato registrado por Renato Murce fornecem algumas pistas. No livro mais direto sobre a estrutura da Rádio em si, é exaltada a tecnologia empregada nos auditórios:

Agora a direção da emissora podia de fato se orgulhar de suas instalações. Nos sete estúdios da PRE 8 se encontravam algumas das mais avançadas inovações, como o piso flutuante sobre molas especiais do palco sinfônico, ou o gigantesco vidro emoldurado em aço e acionado a motor (um conjunto de duas toneladas), pondo em instantes o público do auditório em contato direto com os artistas. (Moreira;Saroldi, 1984, p.35)

Já Mirian Goldfeder tece um comentário a respeito da alteração que houve com relação à cobrança de ingresso para participação do público nos programas de auditório. Segundo a autora, de início gratuito, a entrada nos programas de auditório passou a ter valor cobrado com a finalidade de se estabelecer uma "seleção social de seus frequentadores." (Goldfeder, 1981,p.153) Nessa mesmo linha social dos frequentadores do auditório da Rádio Nacional que Renato Murce, que trabalhou por la cerca de 20 anos, fornece o seu relato:

Na Rádio Nacional, havia dois tipos de auditório: os muito bons para os chamados programas de classe, que não promoviam artistas medíocres, nem distribuíam prêmios com o fim de atrair os seus frequentadores. E os "mesclados", muito ruins, aglutinando uma "fauna" difícil de definir. A Rádio Nacional ficava na praça Mauá. Favorecia, pelo local, essa espécie de frequência para programas "popularescos". Além dos referidos prêmios, procurava-se promover, de 
qualquer maneira, certos artistas. Nunca seus méritos vocais ou cênicos poderiam provocar aquele desmedido entusiasmo dos fãs. (Murce, 1976, p.77)

Apesar do teor preconceituoso de Renato Murce, o que nos interessa aqui é observar essa clara disintição que havia dos diferentes públicos que frequentavam o auditório da Rádio Nacional. Pela descrição de Murce, os programas de Alvarenga e Ranchinho se encaixariam no que ele chamou de "popularesco" visto que eram realizados sorteios envolvendo o patrocinador do programa. Tanto o relato de Murce como dos dados fornecidos por Miriam Goldfeder, ou ainda, o inventário feito pelos autores Luis Carlos Saroldi e Sonia Virginia Moreira, ajudam o pesquisador a traçar uma visão panorâmica daquele programa de rádio que pretende analisar. Observando todos esses fatores que integram a performance dos artistas juntamente com a plateia é possível uma análise mais rica e detalhada dos programas.

Este artigo não pretende encerrar o debate, ao contrário, busco aqui apenas iniciar a discussão sobre essa escuta do passado. Maiores reflexões sobre estes primeiros programas da dupla Alvarenga e Ranchinho integram um dos capítulos presentes em minha dissertação de mestrado que pretendo mais tarde publicar no formato de livro. O objetivo principal aqui é jogar ideias e conceitos a serem discutidos e debatidos por pesquisadores que lidem ou que pretendem lidar com o tema de pesquisa de História e Música.

\begin{tabular}{|c|c|}
\hline Min & Conteúdo \\
\hline $\begin{array}{l}1 \\
1 \\
0\end{array}$ & $\begin{array}{l}\text { - piadas } \\
\text { - 1:22 -4:00 música de abertura } \\
\text { - 4:01 - audição de estreia } \\
\text { - patrocínio Rhum Creosotado } \\
\text { - aniversario do Jorge Curi (piadas com ele) } \\
\text { - versos com o patrocinador }\end{array}$ \\
\hline $\begin{array}{l}8 \\
1 \\
1 \\
0\end{array}$ & $\begin{array}{l}\text { - 6:30 música falando sobre os 'maiorais" } \\
\text { - 7:20 tipos de tosses envolvendo políticos } \\
\text { - conversa por telefone (vozes, personagens..) }\end{array}$ \\
\hline$\stackrel{n}{\stackrel{2}{1}}$ & 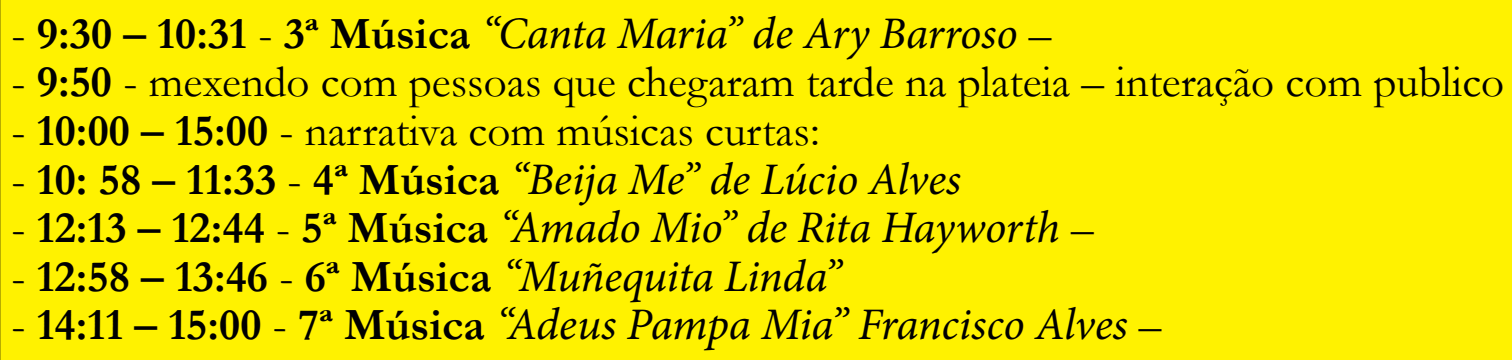 \\
\hline $\begin{array}{l}\text { ㄱ. } \\
\dot{\sigma}\end{array}$ & $\begin{array}{l}\text { - 17:37 - 18:53 } 8^{a} \text { Música "Pan Ran Pan Pan" Sergio de Carlo - } \\
\text { - 19:27 - 20:55 - } 9^{\mathbf{a}} \text { Música paródia de Pan Ran Pan Pan }\end{array}$ \\
\hline 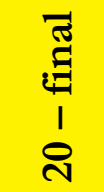 & $\begin{array}{l}\text { - saudação final (“até terça!!”) } \\
\text { - propagandas em versos }\end{array}$ \\
\hline
\end{tabular}


Artigos

\section{Referências bibliográficas:}

BERGSON, Henri. O riso: ensaio sobre a significação do cômico. 2.ed. Rio de Janeiro: Guanabara, 1983.

GOLDFEDER, Miriam. Por trás das ondas da Radio Nacional.Rio de Janeiro (RJ): Paz e Terra, 1981.

MORAES, J. G. V. ; MACHADO, Cacá . Música en conserva. Memoria e Historia de la música en Brasil. In: BRESCIANO, Juan Andrés. (Org.). La memoria histórica y sus configuraciones temáticas. Una aproximación interdisciplinaria. 1 ed. Montevideo: Ediciones Cruz del Sur, 2013, v. , p. 277-303.

MORAES, José Geral Vinci de. História e historiadores da música popular no Brasil. Latin American Music Review, v. 28, p. 271-299, 2007a.

URCE, Renato - Bastidores do rádio: fragmentos do rádio de ontem e de hoje - Imago - 1976 - Rio de Janeiro NAPOLITANO, Marcos. História e Música. Belo Horizonte: Autêntica, 2001 a 172.

História e música popular: um mapa de leitura e questões. Revista de História (USP), v. 157, p. 153

PROPP, Vladimir. Comicidade e Riso. São Paulo: Ática, 1992.

SALIBA, Elias Thomé. Raízes do riso: a representação humorística na história brasileira : da Belle Époque aos primeiros tempos do rádio. São Paulo: Companhia das Letras, 2002

SANT'ANNA, Affonso Romano de. Paródia paráfrase \& cia. 8. ed. São Paulo: Ática, 2007

SAROLDI, Luiz Carlos; MOREIRA, Sonia Virginia. Rádio Nacional: o Brasil em sintonia. 2. ed. Rio de Janeiro: Martins Fontes, 1988.TINHORÃO, José Ramos. Nos Anos de Ouro dos Auditórios. Jornal do Brasil. 1977.

ZUMTHOR, Paul. Performance, recepção, leitura. 2.ed. São Paulo: Cosac \& Naify, 2007.

Anexo

Emissora: Rádio Nacional

Data: 25.02 .47

Dia da semana: terça-feira

Horário: 20:00 horas

Produtores: Alvarenga e Ranchinho

Patrocinador: Rhum Creosotado 